\title{
Assessment of Knowledge and Attitude towards Obstetric Danger Signs During Pregnancy among Pregnant Mothers Attending Antenatal Care in Mizan Aman Public Health Facilities, Bench Maji Zone, South West Ethiopia
}

\author{
Tilahun Mekonnen*, Bitewlegn Girmaye and Fekadu Taye \\ Department of Nursing, Mizan Tepi University, Ethiopia
}

Submission: August 07, 2018; Published: September 06, 2018

"Corresponding author: Tilahun Mekonnen, Nursing Department, Mizan Tepi University, Ethiopia, Email: tilahunmekonnen69@yahoo.com

\begin{abstract}
Background: Knowledge and positive attitude of the danger signs of obstetric complications is the essential first step in the appropriate and timely referral to obstetric care. hence the study intended to assess knowledge and attitude of obstetric danger signs during pregnancy among pregnant mothers attending Antenatal care in Mizan-Amanpubilic Health facilities in bench maji zone SNNPR Ethiopia 2017.

Methods: Institution based cross-sectional study design was used from April 30/2017 to May 30/2017. A total of 223 pregnant mothers was included in the study. The study conducted on pregnant mothers attending Antenatal care in Mizan-Aman public Health Facilities during the time of data collection. Systematic simple rondom sampling technique was used to collect Data using semi structured questionnaire and was analyzed by descriptive analysis method then presented in tables, graphs figures and numerical summery measure.

Result: One handred seventy three (77.5\%) of mothers were knowledgeable about danger sign during pregnancy and $157(70.4 \%)$ and $161(72.2 \%)$ had knowledge about danger sign during labor and postnatal respectively. From the total respondents, $162(72.6 \%)$ had positive attitude and $61(27.4 \%)$ had negative attitude about danger sign of obstetric.

Conclusion: This study showed level of knowledge and attitude about obstetric danger signs during pregnancy, child birth and postpartum period seems like high among women in Mazan Aman public health facility. The most frequently reported obstetric complication during pregnancy, postpartum and child birth and labor is vaginal bleeding. Health profesionals should continue to increase more about knowledge and attitude toward obstetric complications.

Keywords: Danger sign of pregnancy; MTU; Ethiopia

Abbreviations: ANC: Antenatal Care; CI: Confidence Interval; EDH: Ethiopia Demographic Health Survey; ETB: Ethiopian Birr; HEW: Health Extension Workers; IEC: Information, Education and Communication; JHPIEGO: Johns Hopkins Program for International Education in Gynecology and Obstetrics; KA: Knowledge and Attitude; MDG: Millennium Development Goal; MMR: Maternal Mortality Ratio; MOH: Minter of Health; NGO: None Governmental Organization; SNNPR: Southern Nation's Nationality People Regional State; UNICEF: United Nations Children's Fund; UTBA: Untrained Traditional Birth Attendant
\end{abstract}

\section{Introduction}

Pregnancy is a normal process that results in a series of both physiological and psychological changes in expectant mothers. However, normal pregnancy may be accompanied by some problems and complications which is potentially life threatening to the mother and fetus [1]. Pregnancy is a very important event from both social and medical points of view. Therefore, pregnant women should receive special care and attention from the family, community and from the health care system. Anti natal care is a care given to a woman during her pregnancy [2]. The objective of antenatal care (ANC) is to assure that every pregnancy culminates in the delivery of a healthy baby without impairing the health of the mother $[3,4]$.

The new approach to ANC emphasizes the quality of care rather than the quantity. For normal pregnancies WHO recommends only four antenatal visits. The major goal of focused antenatal care is to help women maintain normal pregnancies through: Health promotion and disease prevention, early detection and treatment of complications and existing diseases, 
Birth preparedness and complication readiness planning. Focused ANC protocol is designed as a job aid for ANC providers. It includes revised forms and checklists needed to identify those women that can follow basic care and those women with special health conditions or are at risk of developing complications that needs a special care $[3,5]$. Pregnancy related complications are among the greatest killers of women of reproductive age in developing countries [6].

Danger signs of pregnancies are a warning signs that women encounter during pregnancy, child birth and postpartum. It is important, to know this warning signs for women and health care providers to rule out serious complications and initiate treatment immediately [7]. The most common danger signs during pregnancy that can increase the risk of maternal deaths are: vaginal bleeding, convulsions, high fever, abdominal pain, severe headaches, blurred vision, absence of fetal movements, gush of fluid from vagina, foul smelling vaginal discharge $[7,8]$. Pregnancy complications are the major health problems among women in developing countries. Approximately 529,000 women die from pregnancy related causes annually and almost all (99\%) of these maternal deaths occur in developing countries. The global maternal mortality is unacceptably high [9]. Although there was significant progress in all developing regions, the average annual percentage decline in the global maternal mortality ratio (MMR) was 3.1\%, short of the millennium Development Goals (MDGs) target of 5.5\%. Every day, almost 800 women still die due to pregnancy or child birth, and for every woman who dies 20 or more experience serious complications. One of the United Nations" MDGs is to reduce MMR by $75 \%$ by 2015 [10].

Developing countries account for 99\% (284,000) of the global maternal deaths, the majority of which are in sub-Saharan Africa $(162,000)$ and Southern Asia $(83,000)$. These two regions accounted for $85 \%$ of global burden, with sub-Saharan Africa alone accounting for $56 \%$. The average maternal mortality ratio in developing countries in 2010 was 240 per 100,000 births versus 16 per 100,000 in developed countries reflecting inequities in access to health services, and highlighting the gap between rich and poor. Sub-Saharan Africa had the highest maternal mortality ratio at 500 maternal deaths per 100,000 live births. According to a systematic analysis of progress towards Millennium Development Goal 5 more than $50 \%$ of all maternal deaths in 2008 were in only six countries (India, Nigeria, Pakistan, Afghanistan, Ethiopia, and the Democratic Republic of the Congo) [11].

The situation in Ethiopia is similar to the situation in many developing countries. In Ethiopia the levels of maternal mortality and morbidity are among the highest in the world and the current estimate of MMR is 676 per 100, 000 live births and it is reported that Maternal deaths accounted for $30 \%$ of all deaths to women age 15-49 [12].

Maternal mortality is the leading cause of the adult female deaths in many countries. Women's death during childbirth often means death for the newborn, and both death and disabilities translate into emotional, social, and economic hardships for women's older children, their entire families, and even for communities [13]. Every minute, a woman dies due to causes related to pregnancy, childbirth and postnatal period [14]. Maternal deaths are avoidable, if women with complications are able to identify and seek appropriate emergency obstetric care which makes a difference between life and death [15].

Maternal deaths have both direct and indirect causes. Around $80 \%$ of maternal deaths worldwide are brought about by direct obstetric complications. The five major global causes of maternal death are: severe bleeding (mostly bleeding postpartum), infections (also mostly soon after delivery), unsafe induced abortion, hypertensive disorders in pregnancy (eclampsia) and obstructed labour. Globally, about $80 \%$ of maternal deaths are due to these causes. Hemorrhage alone accounts for one third of all maternal deaths in Africa, yet many of these deaths are preventable. Severe bleeding after birth can kill a healthy woman within two hours if she is unattended. Obstetric fistula resulting from obstructed labor is a long term complication suffered by as many as two million women). Indirect causes such as malaria, diabetes, hepatitis, anemia and other cardiovascular disorders which are aggravated by pregnancy can also lead to maternal death $[1,3]$.

Awareness of the danger signs of obstetric complications is the essential first step in accepting appropriate and timely referral to obstetric and newborn care. Raising awareness of women on danger signs of pregnancy, childbirth and the postpartum period improve mother's attitude to seek medical care and is crucial for safe motherhood [13].

When mothers do not recognize the danger signs in pregnancy, adverse effects can occur to the mother, the unborn baby, or the pregnancy itself. Adverse effects include: Illness or death of the mother, for instance, severe bleeding can lead to anemia or death of the mother, infection to the unborn baby through prematurely ruptured membranes, when amniotic fluid leaks from the vagina. If not attended to, this can lead to fetal or neonatal morbidity and mortality, termination of a pregnancy before term in vaginal bleeding. Maternal hypertension or fever, can lead to increased numbers of neonatal deaths or prematurely born babies who may eventually die due to inadequate facilities to care for them [2].

According to the Ethiopian Federal Ministry of Health, only $10 \%$ of the deliveries are attended by health professionals. In one nation where the maternal mortality ratio is 676 per 100,000 live and IMR 59/1000 and NMR 37/1000 live births which are the highest in the world. In Ethiopia, there is little information about the knowledge and attitude of obstetric danger signs during pregnancy since the introduction of Health Extension Workers (HEWs), despite the national Reproductive strategy aim to raise the awareness to $80 \%$ in the area in which HEW are deployed [16]. 
Studies conducted in Aleta Wondo district, indicated that the knowledge level of pregnant women about obstetric danger signs (during pregnancy, childbirth and postpartum period) was low and affected by residential area. Therefore, the identified deficiencies in awareness should be addressed through maternal and child health services by designing an appropriate strategies including provision of targeted information, education and communication. In spite of great potential of knowledge and attitude of obstetric danger a sign in reducing the maternal and newborn deaths its status is not well known in most of SubSaharan Africa including Ethiopia [17]. This study therefore aims to fill this gap by assessing the current status of knowledge and attitude of danger signs among pregnant mothers attending antenatal care in Mizan Aman public health facilities in Bench Maji Zone SNNPR, Ethiopia.

\section{Methodology}

\section{Study area and period}

This study was conducted at Mizan-Aman town, health facility from march 1-30 2017. The area is located at $565 \mathrm{~km}$ in South west direction from Addis Ababa. There are four wards in the hospital such as Medical, surgical, Gyny, obstetric and pediatrics. There are also one emergency and 30PD. It has 1 gynecologist, 1 general surgeon, 22GP, 11Bsc nurse, 92 diploma nurses, 14 diploma midwifery, 5Bsc midwifery, and 63 other staff. In health center also 22 diploma nurses, 4 midwifery, 1Bsc nurse, 3 pharmacies, 2 public health and 24 others. The hospital providing service to south west Ethiopia and Gambella region for around 8, 50, 538 peoples [18-20].

\section{Study design}

An institutional based cross sectional study design was carried out to assess Knowledge and Attitude of Obstetric Danger Signs During Pregnancy Among Pregnant Mothers Attending Antenatal Care in Mizan Aman Public Health Facilities, Bench Maji Zone, SNNPR, South West Ethiopia [21].

\section{Source population}

All pregnant women who are attending antenatal care (ANC) services in Mizan-Aman health facility [22].

\section{Study population}

All sampled pregnant women attending antenatal care (ANC) at Mizan-Aman health facility during the data collection period.

\section{Inclusion Criteria and Exclusion Criteria}

Pregnant women with gestational age above16 weeks or 4 months were included in the study while pregnant mothers who were unable to hear, speak and severely ill were excluded [23].

\section{Sample size determination}

The sample size was determined using a single population proportion formula by considering 95\% confidence interval, Margin of sampling error 5 and, Prevalence level of Knowledge of obstetric danger signs during pregnancy $24.1 \%$ [17]. After $10 \%$ non-response rate added, thetotal sample size become 223.

\section{Sampling procedure}

Both public health facilities that had been giving ANC service in Mizan-Aman town (MTUTH and Mizan health Center (HC) were included. The sample size was distributed in proportion to average monthly load of previous year of pregnant women who made ANC follow up at each health facility. The total sum of average monthly load previous year ANC of two health facilities is $(N=713)$. The total sample size $(n=223)$ was allocated proportionally to the two (MTUTH and Mizan health Center (HC) care giving public health facilities of Mizan-Aman town according to the number of pregnant women attending antenatal service in the respective health facilities. Then the study participants were systematically selected from each health facilities and pregnant women who were eligible to the study were include in the study by using the " $\mathrm{k}$ " value interval $(\mathrm{k}=713 / 223=3)$, thus every 4 th pregnant women who attended ANC follow up was recruited as study units in each health facilities until the total sample size for this study is obtained. The first pregnant woman was selected based on lottery method.

\section{Study variables}

In this study the dependent variables were Knowledge of obstetric danger signs and Attitude of obstetric danger signs.

\section{Term and Operational Definitions}

\section{Danger signs}

Presence of condition that increases the chances of pregnant woman and/ or her unborn child dying or having poor health. Most common Danger signs are vaginal bleeding, convulsions, high fever, abdominal pain, severe headaches, blurred vision, absence of fetal movements, gush of fluid from vagina, foul smelling vaginal discharge $[24,25]$.

\section{Knowledge}

Knowledge of obstetric danger signs means the basic information that the mothers have regarding obstetric danger signs.

Knowledgeable on key danger signs during pregnancy: If she can mention at least three key danger signs of pregnancy (vaginal bleeding, swollen hands/face, fever, blurred vision, Abdominal pain and Sever head ache) unless not.

Knowledgeable on key danger signs of Labor/child birth: - If she can mention at least three key danger signs for labor/ child birth (sever vaginal bleeding, prolonged labor, convulsions and retained placenta) unless not knowledgeable.

Knowledgeable on key danger signs of post-partum: If she can mention at least Two key danger signs for post-partum (Severe vaginal bleeding, Foul lochia and High fever) unless not knowledgeable.

Attitude: It is an opinion of study participants towards obstetric danger signs. 
Positive attitude: refers to those participants who respond correctly to attitude questions score above mean value.

Negative attitude: refers to those participants who respond correctly to attitude questions score less than mean value.

Informal education: Mothers who were illiterate and can read and write only.

Formal education: Mothers who were primary and secondary school.

High level education: Mothers whose educational status were diploma and above.

\section{Data Collection procedures and instrument}

Data was collected using structured questionnaire. The questionnaire was first prepared in English then translated to Amharic language and retranslated back to the original one to evaluate its consistency. The data was collected by the principal investigators. Before the data collection pre testing was done on $5 \%$ of population from non-sampled individuals [26].

\section{Data quality assurance}

From the beginning the data collection tool was prepared in order to answer the necessary variables, it was discussed, re-evaluated. Data collectors and the supervisor was trained for the necessary approaches, questioners will be checked for completeness, supervisors was taken a role to assure the reliability of the data collected by data collectors, the collected data will be coded appropriately. The data was analyzed appropriately [27].

Result

\section{Socio-demographic characteristics of the study community}

Table 1: Distribution of socio-demographic and economic variables of respondents, In Mizan Aman Public Health Facilities, Bench Maji Zone, South West Ethiopia, 2017.

\begin{tabular}{|c|c|c|c|}
\hline Variable & Category & Frequency, $n=223$ & Percent \\
\hline \multirow{4}{*}{ Marital Status } & Single & 11 & $4.90 \%$ \\
\hline & Married & 203 & $91 \%$ \\
\hline & Widowed & 3 & $1.30 \%$ \\
\hline & Divorced & 6 & $2.70 \%$ \\
\hline \multirow{4}{*}{ Religion } & Orthodox & 69 & $30.90 \%$ \\
\hline & Muslim & 41 & $21.50 \%$ \\
\hline & Protestant & 90 & $40.30 \%$ \\
\hline & Catholic & 23 & $10.30 \%$ \\
\hline \multirow{5}{*}{ Educational Status } & Un educated & 106 & $47.50 \%$ \\
\hline & Read \&write only & 29 & $13 \%$ \\
\hline & Primary education & 41 & $18.30 \%$ \\
\hline & Secondary education & 31 & $13.90 \%$ \\
\hline & Above secondary Educ. & 16 & $7.10 \%$ \\
\hline \multirow{5}{*}{ Occupation } & Merchant & 27 & $12 \%$ \\
\hline & Civil servant & 23 & $10.30 \%$ \\
\hline & Student & 9 & $4 \%$ \\
\hline & Housewife & 133 & $59.60 \%$ \\
\hline & workers(labor) & 31 & $13.90 \%$ \\
\hline
\end{tabular}




\section{Journal of Gynecology and Women's Health}

A total of 223 mothers were enrolled in the study giving a response rate of $100 \%$. Majority 203 (91\%) of participant were married and most $133(59.6 \%)$ of the respondents were housewives. About $\mathrm{n}=90(40.3 \%)$ of the respondents were Protestant while $\mathrm{n}=69$ (30.90\%) were Orthodox followed

\section{Respondent history of gravidity and parity}

Table 2: The respondents' gravidity and parity history, In Mizan Aman Public Health Facilities, Bench Maji Zone, South West Ethiopia, 2017.

\begin{tabular}{|c|c|c|c|}
\hline Variables & Category & Frequency n=223 & Percent \\
\hline \multirow{2}{*}{ ANC Visit } & New & 60 & $27 \%$ \\
\cline { 2 - 4 } & Repeated & 163 & $73 \%$ \\
\hline \multirow{2}{*}{ Gravida } & premigravida & 70 & $31.30 \%$ \\
\cline { 2 - 4 } & multigravida & 153 & $68.70 \%$ \\
\hline \multirow{2}{*}{ para } & $<18$ year & 75 & $33.60 \%$ \\
\cline { 2 - 4 } & $>18$ year & 148 & $66.40 \%$ \\
\hline \multirow{2}{*}{ Number of Baby Born Alive } & $1-2$ & 133 & $59.60 \%$ \\
\cline { 2 - 4 } & $>3$ & 90 & $40.40 \%$ \\
\hline \multirow{2}{*}{ Number of Still Birth } & $1-2$ alive & 121 & $54.2 \%$ \\
\cline { 2 - 4 } & $3 \&$ above & 67 & $30.10 \%$ \\
\hline \multirow{2}{*}{ Number of Children } & $1-2$ & 69 & $13 \%$ \\
\cline { 2 - 4 } & $>=3$ & 63 & $2.70 \%$ \\
\hline
\end{tabular}

Among the entire participant 163 (73\%) had visited ANC more than once while the rest $60(27 \%)$ of the respondent had visited ANC once. Furthermore, out of total number of respondents 153 (68.7\%) had history of 2 and above pregnancies and 70 (31.1\%) mothers had pregnancy once. Regarding first pregnancy age $148(66.4 \%)$ mothers got their first pregnancy at $>18$ years

\section{Knowledge of the respondent about obstetric danger signs}

Table 3: shows respondent Assessment on knowledge obstetric danger signs during pregnancy In Mizan-Aman Public Health Facilities, Bench Maji Zone, South West Ethiopia, June, 2017.

\begin{tabular}{|c|c|c|c|c|}
\hline & Variable & Category & Frequency $n=223$ & Percent \\
\hline \multirow{2}{*}{301} & \multirow{2}{*}{$\begin{array}{l}\text { Having information about obstetric danger sign during pregnancy, } \\
\text { labor and delivery }\end{array}$} & Yes & 174 & $78 \%$ \\
\hline & & No & 49 & $22 \%$ \\
\hline \multirow{4}{*}{302} & \multirow{4}{*}{ Source of information on obstetric danger sign during pregnancy } & 1. Health personnel & 116 & $52 \%$ \\
\hline & & 2. Relative & 13 & $5.80 \%$ \\
\hline & & 3. Friend & 16 & $8.30 \%$ \\
\hline & & 4. Media & 78 & $34.9 \%$ \\
\hline \multirow{6}{*}{303} & \multirow{6}{*}{ Danger signs heared during pregnancy do you know } & 1. Severe vaginal bleeding & 167 & $74.80 \%$ \\
\hline & & 2. Swollen hand\& face & 65 & $29.10 \%$ \\
\hline & & 3. Blurred vision & 88 & $39.40 \%$ \\
\hline & & 4. High fever & 73 & $32.70 \%$ \\
\hline & & 5. Abdominal Pain & 97 & $43.40 \%$ \\
\hline & & 6. Sever head ache & 121 & $54.20 \%$ \\
\hline \multirow{5}{*}{304} & \multirow{5}{*}{ Knowledge on type of danger signs during labor and childbirth } & Severe vaginal bleeding & 136 & $61 \%$ \\
\hline & & Prolonged labour ( $>12$ hours) & 39 & $17.40 \%$ \\
\hline & & Cord prolapse & 45 & $20.10 \%$ \\
\hline & & Convulsion & 78 & $35 \%$ \\
\hline & & Retained placenta & 115 & $51.50 \%$ \\
\hline
\end{tabular}




\begin{tabular}{|c|c|c|c|c|}
\hline \multirow{3}{*}{305} & \multirow{3}{*}{ Knowledge on type of danger signs during postpartum period } & 1. Severe vaginal bleeding & 62 & $27.80 \%$ \\
\hline & & 2. Foul lochia & 129 & $58 \%$ \\
\hline & & High fever & 32 & $14.30 \%$ \\
\hline
\end{tabular}

About 174 (78\%), mothers have information about obstetric danger signs and 116 (52\%) heard about danger sign from health personnel followed by media 56 (25\%). From those who had the information,167(74. 80\%) identified severe vaginal bleeding at any time during pregnancy as danger sign. Swelling of the body 65 (29.1\%), persistent headache 121 (54.20\%), Abdominal pain 97(43.4\%) blurred vision 88 (39.4\%), and High fever $73(32.7 \%)$ were also indicated by the study subjects as danger sign. Severe vaginal bleeding was the most frequently mentioned complication by women during pregnancy by 167 (74.80\%), labor by 139 (61\%) and postpartum period by 61 (27.3\%) respectively (Table 3 ) [33].

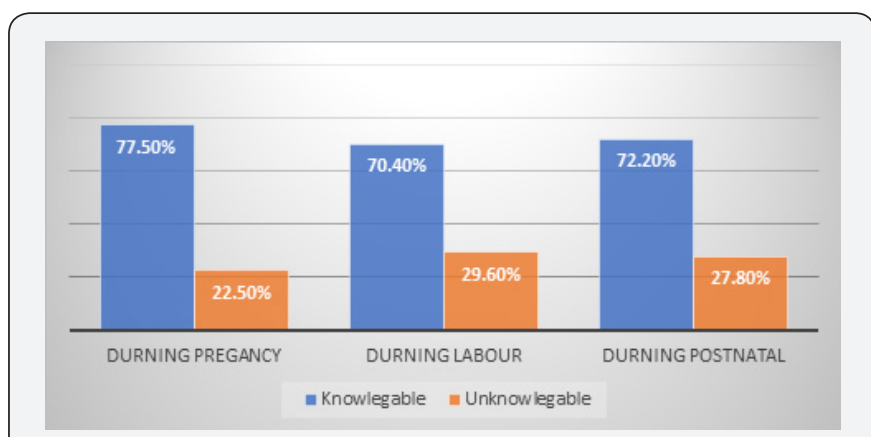

Figure 1: Level of knowledge about Obstetric danger sign.

Generally,173 (77.5\%) of mothers were knowledgeable about danger sign during pregnancy and 157(70.4\%) and $161(72.2 \%)$ had knowledge about danger sign during labor and postnatal respectively (Figure 1).

\section{Attitudes of the respondent towards danger signs during pregnancy}

From the total respondents, 162(72.6\%) had positive attitude and $61(27.4 \%)$ had negative attitude about danger sign of obstetric (Figure 2) [34].

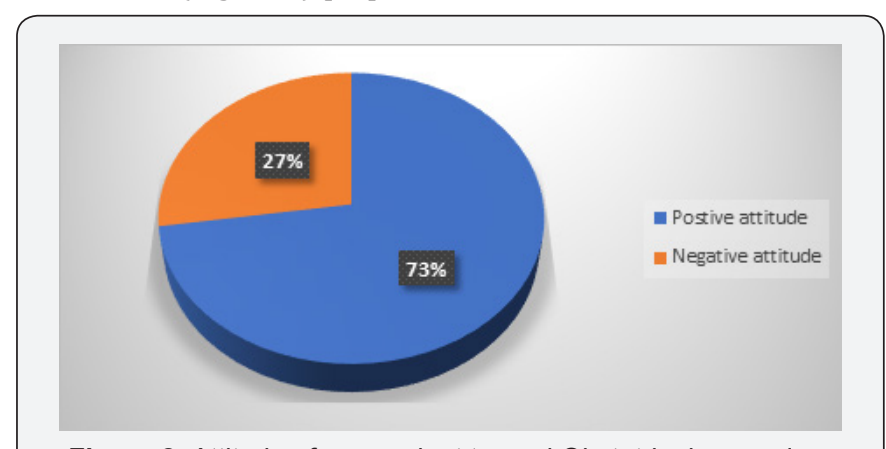

Figure 2: Attitude of respondent toward Obstetric danger sign.

\section{Discussion}

In this study, mother's level of Knowledge about danger signs of obstetric complications during pregnancy, labor and postnatal was $77.5 \%, 70.4 \%$ and $72.2 \%$. This finding is higher than the study done in Goba district that shows $31.9 \%, 27 \%$ and $22.1 \%$ of study participants knew at least three key danger signs during pregnancy, delivery and postpartum period, respectively [35]. The variation of result is due to difference in study period and difference in study area. As compared to the studies done in past, it seems increased because of the current health policy being applied is increasing the awereness about obstetric complication to prevent maternal and child death. Vaginal bleeding was the most recognized obstetric danger sign all, during pregnancy, $74.8 \%$, labor, $61 \%$ and postpartum period $27.3 \%$. This is in line with the studies conducted in different countries [6].

In this study, $72.6 \%$ of mothers had positive attitude on prevention of obstetric danger sign during pregnancy. This is almost compatible with the study conducted in Debre Birhan city that stated $88 \%$ the study participants agreed that knowing obstetric danger signs is important to seek medical care on time, $57 \%$ of the respondents were agreed on prevention of obstetric danger signs and $71.2 \%$ disagree on the idea that mothers who develop obstetric danger signs should seek help from traditional birth attendants. The possible reason for this variation was due difference in study area and due to this study was done on facility this may contribute to the diffirence. This also shows attitude of the women being increased dou to different activities being implemented in health facilities changed the attitude of women. As any cross sectional study this study has strength and weakness. The strength is that the study was done at risky population group while the limitation is, since this study is facility based it may not indicate the finding in community.

\section{Conclusion}

This study shows even though the level of knowledge and attitude of women about danger signs of obstetric complication among pregnant women attending ANC follow up in Mizan Aman health facility seems high as compared to past studies, it is not sufficient to prevent the burden related to complication during pregnancy, labor and postnatal. The most frequently cited obstetric complication during pregnancy, postpartum and child birth and labor was vaginal bleeding.

\section{Declarations}

\section{Ethics approval and consent to participate}

This study was not involved in any experiment on human subjects. The written consent was taken from the respondents just before data collection. Ethical approval was obtained from Mizan Tepi University Collage of Health Sciences, Institutional Review Board to communicate with hospital administrative body. Permission letter was obtained from administrative body of Mizan Tepi University teaching hospital.

\section{Competing interests}

The authors declare that they have no competing interests. 


\section{Funding}

The study was funded by Mizan Tepi University.

\section{Authors' contributions}

The authors' responsibilities were as follows: All authors designed, supervised the study, ensured quality of the data and assisted in the analysis and interpretation of the data. All authors critically reviewed the manuscript. The corresponding authors did the analysis \& drafted the manuscript and had the responsibility to submit the manuscript for publication.

\section{Acknowledgement}

We wish to express our gratitude to Mizan Tepi University, department of Nursing for providing the opportunity and our study participants.

\section{References}

1. Wafaa R, Rasha E (2010) Women's awareness of danger signs of obstetrics complications. Journal of American Science 6: 10.

2. (2004) Lecture note on ObyGyny for nursing students by Meselech Assegid \& Alemaya university, Ethiopia.

3. World Health Organization (1998) Pregnancy is special let's make it safe: Special feature-safe motherhood facts. Safe Mother 25: 4-9.

4. Federal Ministry of Health (FMOH) (2006) Healthand Health Related Indicators. Ethiopia.

5. USAID (2008) Working toward the goal of reducing maternal and child mortality: USAID programming and response to FY08 appropriations, USA.

6. Kabakyenga KJ, Ostergren P, Turyakira E, Pettersson KO (2011) Knowledge of obstetric danger signs and birth preparedness practices among women in rural Uganda. Reproductive health 8(10): 33.

7. Hussein J, Kanguru L, Astin M, Munjanja S (2012) The effectiveness of emergency Obstetrics referral interventions in developing countries: Settings a systematic review. PLoS med 9: 7.

8. UNICEF (2010) A Global Overview of Maternal Mortality.

9. UNFPA (2011) Safe Motherhood Stepping up Efforts to Save Mothers Lives.

10. WHO (2012) Trends in Maternal Mortality: 1990 to 2010, WHO, UNFPA, UNICEF and World Bank. Geneva 3(2): 41.

11. Central Statistical Agency and ORC Marco (2011) Ethiopian Demographic and Health Survey, USA.

12. JHPIEGO (2004) Monitoring birth preparedness and complication readiness: tools and indicators for Maternal and Newborn health Programs, USA.

13. Abouzahr C (2003) Safe Motherhood: a brief history of the global movement 1947-2002. Br Med Bull 67: 13-25.

14. WHO (2015) Why do so many women still die in pregnancy or childbirth?

15. FMOH (2006) Federal Democratic Republic of Ethiopia, Ministry of Health. National Reproductive Strategy, 2006-2015. Ethiopia, pp. 1621.

16. Hailu M, Gebremariam A, Alemseged F (2010) Knowledge about obstetric danger signs among pregnant women in Aleta Wondo district, Sidama Zone, Southern Ethiopia. Ethiop J Health Sci 20(1): 25-32.
17. USAID (2010) Family Planning and Reproductive Health Indicators Database. Existence of a safe motherhood strategic plan to promote access and quality of safe motherhood services. Measure Evaluation Population and Reproductive health.

18. Hasan IJ, Nisar N (1999) Women's Perceptions regarding Obstetric Complications and Care in a Poor Fishing Community in Karachi, pakistan.

19. Marco A (2003) Knowledge and practice of maternal health care in Indonesia.

20. WHO (2009) Maternal, Neonatal, and child health. Strategy Global Health program.

21. Congo C (1885) A study to determine knowledge attitude and practice of women in child bearing age towards danger signs in pregnancy in Lusaka, urban Lusaka.

22. Agboatwalla M, Akram DS (1997) Impact of Health education on mothers" knowledge of preventive health practices, Karachi Pakistan. Trop Doct 27(4): 199- 202.

23. Nepal (2005) Improving Maternal, Newborn and Child Health in the South East Asia Region. Maternal and reproductive health, p. 84.

24. Perreira KM, Bailey PE, Bocaletti DE, Hurtado E, Recinos DVS, et al. (2002) Increasing awareness of danger signs in pregnancy through community and clinic based education in Guatemala. Maternal Child Health Journal 6(1): 19-28.

25. Urassa DP, Pemba AB, Mganga F (2012) Birth preparedness and complication readiness among women in Mpwapwa district, Tanzania. Tanzan J Health Res 14(1): 42-47.

26. Ali AA, Rayis DA, Abaker AO, Adam I (2010) Awareness of danger signs and nutritional education among pregnant women in Kassala, Eastern Sudan. Sudanese Journal of Public Health 5(4): 179-181.

27. Anya SE, Hydara A, Jaiteh LES (2007) Antenatal care in The Gambia: Missed opportunity for information, education and communication. BMC Pregnancy and Childbirth 8: 9.

28. Cham M, Sundby J, Vangen S (2005) Maternal mortality in rural Gambia, a qualitative study on access to emergency obstetric care. BMC Reproductive Health 2: 3 .

29. Sarode VM (2010) Does illiteracy influence pregnancy complications? Among women in the slums of greater Mumbai. International Journal of Sociology and Anthropology 2(5): 82-94.

30. Pembe AB, Urassa DP, Carlstedt A, Lindmark G, Nyström L, et al. (2009) Rural Tanzanian women's awareness of danger signs of obstetric complications. BMC Pregnancy Child birth March 9: 12 .

31. Sodere N (2014) Assessment of Kap Of Obstetric Danger Signs During Pregnancy Among Mothers in Debre Birhan City Administration, North Shewa Zone, Amhara, Ethiopia.

32. Yinager W, Desta H, Teklemariam G, Nega D, Minale M, et al. (2014) Knowledge of Obstetric Danger Signs and its Associated Factors in Arba Minch Town, Ethiopia. American Journal of Health Research 2(5): 255-259.

33. Hailu D, Berhe H (2014) Knowledge about Obstetric Danger Signs and Associated Factors among Mothers in Tsegedie District, Tigray Region, Ethiopia 2013: community based cross-sectional study. PLoS One 9(2): e83459.

34. Bogale D, Markos D (2015) Knowledge of obsytric danger signs among child bearing age of women in Goba district, Ethiopia: a cross-sectional study. BMC Pregnancy Childbirth 15: 77.

35. Sodere N (2014) Assessment of Kap Of Obstetric Danger Signs During Pregnancy Among Mothers in Debre Birhan City Administration, North Shewa Zone, Amhara, Ethiopia. 
Your next submission with Juniper Publishers will reach you the below assets

- Quality Editorial service

- Swift Peer Review

- Reprints availability

- E-prints Service

- Manuscript Podcast for convenient understanding

- Global attainment for your research

- Manuscript accessibility in different formats

( Pdf, E-pub, Full Text, Audio)

- Unceasing customer service

Track the below URL for one-step submission https://juniperpublishers.com/online-submission.php 